\title{
Derivation of Spatially Distributed Thermal Comfort Levels in Jordan as Investigated From Remote Sensing, GIS Tools and Computational Methods
}

ibrahim M. oroud ( $\square$ ioroud@mutah.edu.jo)

Mu'tah University

\section{Research Article}

Keywords: big data, thermal comfort, spatially distributed maps, evaporative cooling, climate data, Jordan

Posted Date: November 17th, 2021

DOI: https://doi.org/10.21203/rs.3.rs-1069123/v1

License: (9) This work is licensed under a Creative Commons Attribution 4.0 International License.

Read Full License

Version of Record: A version of this preprint was published at Theoretical and Applied Climatology on February 4th, 2022. See the published version at https://doi.org/10.1007/s00704-022-03951-7. 
Derivation of spatially distributed thermal comfort levels in Jordan as investigated from remote sensing, GIS tools and computational methods

Ibrahim M. Oroud

Mu'tah University

Jordan

ioroud@mutah.edu.jo 
Derivation of spatially distributed thermal comfort levels in Jordan as investigated from remote sensing, GIS tools and computational methods

\section{Abstract}

Thermal comfort is usually calculated using discrete point measurements. This procedure is not suitable to study thermal comfort for inhabited areas with rugged terrains where climate gradient is high. The wide availability of remote sensing data and GIS tools have revolutionized data management, processing and visualization. The present paper implemented digital elevation data, GIS tools and a computational algorithm to generate spatially continuous maps of climatological elements which were employed to derive thermal comfort levels across Jordan. Results show detailed information of the spatial distribution of the degree of thermal comfort in winter and summer across the country which cannot be resolved using discrete point measurements. It is shown that the mountainous areas in the country, where most urban centers are situated, experience "slightly warm" to "warm" indoor apparent temperatures in summer. The Jordan Valley and the desert experience high indoor apparent temperatures in summer. Cold conditions prevail over most parts of the country, with the heating degree days ranging from 2100 in the southern mountains to values close to zero near the Dead Sea area. The presented procedure demonstrated that the very low levels of ambient vapor pressure is an important atmospheric forcing contributing to the widespread cold conditions prevailing over the desert areas in winter. The efficiency of direct evaporative cooling systems to achieve thermal comfort in the various parts of the country is investigated. The procedure presented can be used over regional scales with different levels of spatial resolutions for a wide range of climatological studies.

Keywords: big data, thermal comfort, spatially distributed maps, evaporative cooling, climate data, Jordan

\section{1- Introduction}

Thermal comfort is a bioclimatic indicator reflecting the level of thermal comfort/discomfort within a climate regime during a specific period of time. The American Society of Heating, Refrigerating and AirConditioning Engineers (ASHRAE, 2009) defines thermal comfort as "the condition of mind that expresses satisfaction with the thermal environment and is assessed by subjective evaluation" (Fergus, 2001). Energy consumption, outdoor working conditions, recreational activities, environmental tourism and many other economic activities are strongly influenced by the level of thermal comfort (De Dear and 
Brager, 2002; Humphreys and Fergus, 2000; Orosa, 2009). Thermal comfort index can be used to estimate energy demands needed for heating and cooling purposes during the annual cycle.

Unusual weather conditions could pose a threat to human lives. For instance, high temperatures and elevated humidity have been reported to increase hospitalization and death rates among vulnerable age group (Anderson et al. 2013; Basu et al. 2010). The scenarios of increased air temperature caused by global warming could exacerbate thermal discomfort in many regions across the globe, rendering living conditions rather very difficult or very expensive (Marx et al. 2021; Mistry, 2020). There is an increased risk of more frequent heat waves following a climate change (Meehl and Tebaldi 2004). Ill health and mortality rate are endangered by temperatures outside the thermal comfort range. Physiological, psychological and environmental parameters such as metabolic heat generation, age, clothing, mean radiant temperature, ambient relative humidity, airflow rate and heat gain from radiation source work hand in hand to influence the perception and degree of thermal comfort (Steadman, 1979a,b; Schweikera et al., 2017). Thermal comfort is usually assessed using point measurements due usually to the limited number of observational sites and the ease to generalize results (Fang et et al., 2004; Fang; Oliveira and Andrade, 2007; Orimoloye et al., 2017). Spatially continuous thermal comfort levels were derived for global or continental scales (Matzarakis and Amelung, 2008; Mistry, 2020; Yan et al., 2021). These representations are useful to develop a general idea of thermal comfort over different geographic zones. Due to their very coarse spatial resolutions, these procedures cannot be used for operational purposes, particularly in areas with rugged terrains. The increased capabilities of computational power along with the availability of fine resolution spatially gridded elevation data and the interpolation capabilities of GIS tools have revolutionized data management, and thus large volumes of data could be generated, processed, and visualized across regional scales. Thus, the objective of the present investigation is to derive spatially continuous thermal comfort levels across Jordan using digital elevation data, GIS tools and limited meteorological data. The generated maps provide objective means to identify the spatial distribution of thermal comfort across the study area. The procedure could be extended to evaluate energy demands for heating and cooling purposes, suitability of different areas for evaporative cooling and to locate suitable sites for recreational activities and other tourism purposes.

\section{2- Study area}


The present procedure is applied to the country of Jordan. Jordan extends from $29.19^{\circ}$ to $33.35^{\circ} \mathrm{N}$ and from $34.95^{\circ}$ to $39.3^{\circ} \mathrm{E}$, with a total surface area of $\sim 90000 \mathrm{~km}^{2}$ (Figure 1). The study area spans wide topographic variations, with the elevation ranging from $250-436 \mathrm{~m}$ below mean sea level near the Dead Sea area and along the Jordan Valley to more than $1700 \mathrm{~m}$ in the southern mountains. There is a steep elevation gradient across the east-west direction, and as a result, a steep climate gradient exists across the east-west and in the north- south directions. Figure 2 shows the topography of the study area. Precipitation in this area ranges from a few $\mathrm{mm} / \mathrm{year}$ in southeastern Jordan to about $600 \mathrm{~mm} / \mathrm{year}$ in a small enclave in the northwestern part of the country. Air temperature depends on the elevation and longitude, with the average annual temperature ranging from $26.5^{\circ} \mathrm{C}$ near the southern Dead Sea to about $14{ }^{\circ} \mathrm{C}$ in the southern mountains.

\section{Method of investigation}

3.1 Remote Sensing data and GIS tools

Digital elevation data (DEM) were downloaded from the Shuttle Radar Topographic Mission (SRTM) from the USGS site. The DEM data have a geographic coordinate system and a spatial resolution of one $\operatorname{arc} \operatorname{second}(\approx 30 \mathrm{~m})$. The DEM image was reprojected to the UTM coordinate system, zone 36 to allow proper computation of distances across the grids. To facilitate processing of this very large dataset, the DEM data were resampled to one km spatial resolution. Arc Map (version 10.7) was used to extract the coordinates and elevation of each grid point. Generated coordinates and elevation for each grid were exported to a csv file for further processing by the numerical model. Figure 3 presents a flow chart of method used in this investigation.

\section{2- Climatological data}

Meteorological stations in Jordan are relatively sparse and poorly distributed, and thus climate elements over large parts of the country are not monitored, rendering these area as "blind spots". Twenty-two meteorological stations were used to carry out the calculation of the thermal comfort index. The average monthly temperature and relative humidity for the meteorological stations were obtained from the Department of Meteorology, Jordan. Table 1 shows the coordinates, elevation, average monthly air temperature and relative humidity of the stations used in this investigation. To improve the integrity of the model and provide a better representation of the study area, five additional stations were synthetically generated. This was done primarily along the Dead Sea and in Wadi Araba due to the scarcity of measuring stations. The temperature and relative humidity of each synthetic 
station were derived based on field measurements and a few other criteria including its elevation, the general climate pattern of the nearest measuring stations, wind regime and energy balance considerations (Oroud, 1997).

3.3 Numerical procedure

Interpolation by GIS tools is purely spatial, and thus climate gradient induced by elevation differences across a landscape is usually masked out. The problem of GIS interpolation can become severe if weather measuring stations are sparsely distributed over very rugged terrains (e.g., Jeffrey et al., 2001; Apaydin et al., 2004). In this case direct interpolation techniques in the GIS environment do not produce adequate results, and large deviations may result. Under such conditions, a better procedure to generate accurate data between measuring sites would be to build a numerical procedure which takes into account the neighboring measuring sites along with vertical and horizontal gradient of the intended climate elements across the landscape. The computational procedure provides an explicit algorithm to calculate meteorological elements at each grid point. This procedure produces a dense point network which enables GIS to produce accurate spatially distributed raster database.

Two steps are needed to generate climatological data over a spatial grid. The one is obtaining the distance between the grid and measuring sites, and the second one is calculating the climatological element using the closest $\mathrm{n}$ stations after taking into account the elevation difference between each measuring site and the spatial grid.

The Euclidean distance between grid $\mathrm{j}$ and a measuring site is computed as,

$$
\delta_{i, k}=\sqrt{\left(x_{i}-x_{j}\right)^{2}+\left(y_{i}-y_{j}\right)^{2}}
$$

where $\delta_{\mathrm{i}, \mathrm{k}}$ is the Euclidean distance $(\mathrm{m})$ between station $\mathrm{i}$ and the intended grid cell, and the $\mathrm{x}$ and $\mathrm{y}$ are the easting and northing coordinates $(\mathrm{m})$.

The temperature of each grid $\left(\mathrm{T}\left(\mathrm{x}_{\mathrm{k}}, \mathrm{y}_{\mathrm{k}}, \mathrm{z}_{\mathrm{k}}\right)\right.$ was calculated explicitly using the inverse distance weighting procedure (IDW) using the following equation (Emmendorfer and Dimuro, 2020),

$$
T\left(x_{k}, y_{k}, z_{k}\right)=\sum_{i=1}^{j}\left(T i+\Gamma(z i-z(k)) / \delta(i, k)^{2} /\left(\sum_{i=1}^{j} \frac{1}{\delta(i, k)^{2}}\right)\right.
$$

where $x_{k}$ is the easting $(m), y_{k}$ is the northing $(m)$ and $z_{k}$ is the elevation of the grid; $T_{i}$ is the temperature of station $\mathrm{i}, \Gamma$ is the environmental lapse rate $\left({ }^{\circ} \mathrm{C} \mathrm{m}-1\right), \mathrm{z}_{\mathrm{i}}$ is the elevation of station $\mathrm{i}, \mathrm{z}(\mathrm{k})$ is 
the elevation of the grid, and $\delta(\mathrm{i}, \mathrm{k})$ is the Euclidean distance between station $\mathrm{i}$ and the intended cell. In this procedure, the closest three stations were chosen to carry out the interpolation of temperature for each grid (the j parameter in Eqn. 2).

$$
\delta(i, k)=\min \left(\delta_{i}, \delta_{i+1}, \ldots, \delta_{n}\right)
$$

The actual vapor pressure is computed from the interpolated relative humidity and saturation water vapor pressure at each grid,

$$
e_{a}=R H \times e_{s}
$$

where $R H$ is the relative humidity $(\%), \mathrm{e}_{\mathrm{a}}$ and $\mathrm{e}_{\mathrm{s}}$ are the actual and saturated vapor pressure $(\mathrm{kPa})$, respectively. The saturation vapor pressure at a grid is calculated using the following form (Oroud, 2011),

$$
e_{s}=0.61078 \exp \left(\frac{17.269 T}{(237.3+T)}\right.
$$

Where $\mathrm{T}$ is the grid temperature $\left({ }^{\circ} \mathrm{C}\right)$.

The wet bulb temperature which is an important indicator of the evaporating power of air is usually used to assess the efficiency of using evaporative cooling systems. The wet bulb temperature is calculated for each grid from air temperature and relative humidity of the interpolated grid using the procedure presented by Stull (2011) expressed as,

$\left.W B T=T_{a}+\operatorname{atan} \sqrt{(0.151977 \times(R H+8.313659)}\right)+\operatorname{atan}\left(T_{a}+R H\right)-\operatorname{atan}(R H-$

$\left.1.67633)+0.00391838 \times R H^{1.5} \times \operatorname{atan}(0.023101 \times R H)\right)-4.686035$

where $W B T$ is the wetbulb temperature, Ta is air temperature, atan is the arctangent of the expression expressed in radian, and $R H$ is the relative humidity (\%).

3.4 Thermal comfort index

Numerous methods have been suggested in the literature to provide a quantitative metric to gauge thermal comfort (Anderson et al., 2013; Brager et al., 1998). The most accurate method would be to use a detailed energy budget equation in which heat gain and loss from the human subject are taken into account (Fang et al., 2004; Orosa, 2009; Steadman, 1984). Because of the complex nature of thermal comfort due to the many environmental, physiological and psychological factors involved, simple empirical equations have been developed to provide an approximate representation of the level of thermal comfort/discomfort in indoor and outdoor conditions (Fabbri, 2015; Steadman, 1979a,b). 
Thermal comfort for unconditioned buildings is controlled by meteorological elements of the outside environment. De Dear and Brager (2002), Humphreys and Fergus (2000) indicated a close link between the effective temperature of unconditioned buildings and outdoor air temperature. In many third world countries, buildings are not air conditioned due to lack of financial resources required to achieve thermal comfort, and thus thermal comfort of these dwellings respond directly to outdoor meteorological conditions.

Numerous thermal comfort indices exist in the literature such as the heat index, humidex, wet-bulb globe temperature, apparent temperature (Fabbri, 2015; Orosa, 2009; Orimoloye et al., 2017; Tseliou et al., 2010). Most indices use air temperature and a psychrometric variant- e.g., relative humidity, ambient vapor pressure, dew point or wet bulb temperature (ASHRAE, 2009; Anderson et al., 2013). Some indices use additional environmental variables such as wind speed and solar radiation. The major differences among most indices are in the empirical coefficients used in each algorithm. Anderson et al (2013) compared 21 thermal index algorithms and concluded that most of them generate values which are consistent with the apparent temperature as presented by Steadman (1978 a, b). Detailed discussions of the various thermal indices and methods to calculate each of them was presented by numerous authors (e.g., Anderson et al., 2013; Blazejczyk et al., 2010; Mistry, 2020).

The elegance of algorithms using air temperature and humidity is their simplicity and the wide availability of required parameters. Popular thermal indices which use only air temperature and a humidity element include the Discomfort Index, the temperature-humidity Index, the Humidex, and the Ambient Indoor Index (e.g., Orimoloye et al., 2017; Yan et al., 2021). The Discomfort Index (DI), the indoor apparent temperature (IAT), the Temperature- Humidity Index (THI) and the Humidex may be respectively written using the following form (Anderson et al., 2013),

$$
\begin{gathered}
D I=8.3+0.4\left(W B T+T_{a}\right) \\
I A T=-1.3+0.92 T_{a}+0.22 e_{a} \\
T H I=T_{a}-(0.55-0.0055 R H)\left(T_{a}-14.44\right) \\
\text { Humidex }=T_{a}+0.555\left(e_{a}-10\right)
\end{gathered}
$$

where WBT is the wet bulb temperature ${ }^{\mathrm{O}} \mathrm{C}, \mathrm{e}_{\mathrm{a}}$ is the ambient vapor pressure in $\mathrm{hPa}, \mathrm{T}_{\mathrm{a}}$ is the ambient air temperature ${ }^{\mathrm{O}} \mathrm{C}$, and $\mathrm{RH}$ is the relative humidity of air in $\%$. The apparent indoor temperature and the temperature humidity index can be used during the different seasons. In this investigation, the IAT 
is chosen to calculate thermal comfort because it can be calculated for a wide range of ambient conditions and computed values were found to compare favorably well with the Universal Thermal Climate Index (UTCI) (Blazejczyk et al., 2012; Mistry, 2020). Table 2 shows the designation of the thermal comfort categories and corresponding IAT values (Matzarakis and Amelung, 2008)). There is correspondence between the values of these indices and thermal comfort/ human activity. For instance, when the IAT rises above 35, considerable discomfort is common, work efficiency is compromised, and physical activity should be reduced or stopped altogether (Schlatter, 1987).

4- Results

\subsection{Air temperature}

Outside air temperature is a good indicator of thermal comfort within unconditioned buildings. Figure 4 shows the spatial distribution of average monthly air temperature during January and July, respectively. Wide temperature differences are observed across the study area during these two months. A distinct temperature gradient is very clear along the Jordan Valley in both months. For instance, the average temperature in January ranges from $\sim 3^{\circ} \mathrm{C}$ in the high southern mountains to more than $16{ }^{\circ} \mathrm{C}$ in the Jordan Valley close to the Dead Sea. An important observation for January is the prevalence of low temperatures in the desert areas which cover the eastern and southeastern areas of the country. Although desert areas receive relatively more solar radiation than the mountainous areas during the daytime hours in winter, thermal radiation deficit there is very high during winter due to clear skies and low moisture content in the troposphere.

The summer months, as represented by July, display a different spatial temperature distribution pattern compared to January. Unlike winter, desert areas experience high temperatures in summer, and the near surface air temperature of some of these locations rival those along the Jordan Valley despite the significant elevation differences between the Jordan Valley and desert areas. All locations along the Jordan Valley are situated much below sea level- $\sim 250-430 \mathrm{~m}$ below sea level, whereas the desert landscape has elevations ranging from $550 \mathrm{~m}$ to more than $1000 \mathrm{~m}$ above mean sea level.

\subsection{The indoor apparent temperature}

The spatial distribution of indoor apparent temperature is presented in Figure 5 for January and July as the two endpoints of the annual cycle. The Jordan Valley attains very high IAT values during July, with average values ranging from 30 to more than $36^{\circ} \mathrm{C}$. Comfortable conditions during summer are restricted to the southern mountains and a few other highland enclaves in central and northern Jordan. 
With the exception of weather conditions associated with heat waves, the mountainous areas in Jordan where most urban centers are situated can be classified on average as "slightly warm". The northwestern part of the country and the central part appear on the map as being on the warm side; this is due to low elevation and high vapor pressure content in the atmosphere. A strong indoor temperature gradient exists between the mountains and the desert in the east and southeast. In addition to the large amount of solar radiation reaching their surface, desert surfaces are devoid of vegetation cover, transforming all surface net radiation into subsurface heat storage and sensible heat flux to the contiguous atmosphere (Oroud, 2020). As a result of the strong surface and near surface heating during summer, thermal comfort levels in a large portion of the desert areas are very close to those encountered in the Jordan valley.

The spatial distribution of indoor apparent temperature in winter (Figure 5.b) differs drastically from corresponding values in July. With the exception of the Jordan Valley which maintains relatively pleasant thermal comfort levels, most other areas experience cold or very cold conditions during winter. The indoor apparent temperature ranges from very cold as in the southern mountains to cold in the reset of the country. Surprisingly, most of the mountainous areas in northern Jordan experience more amenable thermal comfort levels compared to desert areas in winter. The relatively less harsh thermal conditions in the northern mountains during winter, despite their higher elevations compared to the desert areas, are likely linked to larger soil moisture and the greater probability of cloud cover during the nighttime hours.

Although desert areas are relatively hot in summer, cold conditions are widespread during the winter months. Surface thermophysical properties and atmospheric forcings can be cited for the anomalously cold conditions in the desert areas in winter. Desert areas have usually dry coarse bare surfaces which have low thermal conductivity, and thus the layer involved in warming up/cooling processes during the diurnal cycle is rather very shallow, leading to rapid and extensive cooling during the long night hours. Two additional atmospheric factors enhance nighttime cooling- the first one is the usual absence of cloud cover, and the second factor is the low moisture content in the troposphere. Figure 6 shows the spatial distribution of actual vapor pressure across the country. It is clear that desert areas are characterized with very low actual vapor pressure due to lack of soil moisture on the one hand and their remoteness from water bodies. The dewpoint temperature as inferred from Figure 6 is either close to zero or below zero over a large portion of the desert areas. Thus, the very low dewpoint temperatures 
across the desert in winter explain the widespread cold conditions in this area. A strong correlation exists between thermal comfort and elevation as presented in Figure 7. The correlation coefficient in January is $\sim 0.97$ whereas its corresponding value in July and August is $\sim 0.92$ and 0.93 , respectively. Summer has a larger lapse rate than winter, with values of $0.67{ }^{\circ} \mathrm{C} / 100 \mathrm{~m}$ and $0.8^{\circ} \mathrm{C} / 100 \mathrm{~m}$ in January and July/August, respectively.

Unlike point measurements which provide information in the immediate vicinity of the measuring site, the present procedure is able to map thermal comfort continuously across a very large, rugged area with substantial climate gradients. This point is evident when inspecting the indoor apparent temperature gradient between the mountains and the Jordan Valley. Furthermore, the present procedure is able to establish a physical link between the widespread cold conditions over the desert and the spatial distribution of actual vapor pressure.

4.3 Implications for heating and cooling

Results presented in this investigation can be extended to examine the heating and cooling load for any specific location during the course of year. Figure 8 shows the average monthly indoor apparent temperature for twenty-two locations, many of which are situated in or close to major urban centers. This table shows that most areas in Jordan experience cold conditions during winter months and as such require a large investment of energy- fuel/gas/ electricity- to meet heating requirements of occupied buildings like offices and homes. Most locations in Jordan require heating from November to the end of March but with wide variations. This point raises an important issue regarding the wisdom of specifying the beginning of November as the starting date for winter in Jordan. This date implies that public offices are allowed to use heating systems regardless of the location of the building whether it is near the Dead Sea or in the high southern mountains. Results presented in this paper provide some guidelines of the different thermal comfort zones in the country during winter. Heating requirement for each location can be determined roughly from Figure 8 . For instance, the heating degree days for a base temperature of $18{ }^{\circ} \mathrm{C}$ may range from $\sim 2200$-degree days in the southern mountains to 145-degree days near the southern corner of the Dead Sea. Mountainous and desert locations require on average between 1000-1400- degree days of heating. Cooling is definitely not as demanding as heating in most locations in the country. Cooling may be required in the late afternoon hours in most large urban centers during July, August and September. 
The Jordan Valley and desert areas require a great deal of energy investment for cooling purposes to bring about thermal comfort.

To cutdown on energy spending, direct evaporative cooling systems are usually employed in lowincome communities (Basediya et al., 2013; Camargo, 2013). Evaporative cooling systems use only water and a blower to cool unsaturated air when forced through a water-saturated porous medium. The temperature of blown air is cooled down via evaporating water from the saturated medium. This mode is characterized by very low energy consumption compared to refrigerating units. A major factor influencing the use of evaporative cooling for thermal comfort purposes is the wet bulb temperature, which can be used to gauge the efficiency of this cooling mode. Figure 9 displays the spatial distribution of the wet bulb temperature along with the major urban centers. Evaporative cooling systems have an efficiency of 50\% to 70\% (e.g., Basediya et al., 2013; Camargo, 2013). For instance, the blown air passing a porous saturated medium can be expressed as (Basediya et al., 2013),

$$
T_{\text {out }}=T_{\text {in }}-\alpha\left[T_{\text {in }}-T_{w b}\right]
$$

Where $T_{\text {out }}$ is the resulting air temperature after passing through the saturated medium, $T_{\text {in }}$ is the blown outside air, $\alpha$ is the efficiency of the cooling system, and $\mathrm{T}_{\mathrm{wb}}$ is the wet bulb temperature. The efficiency of the cooling system is a measure of how closely the supply air temperature leaving the evaporative cooler approaches the outdoor wet-bulb temperature. A psychrometric chart can be consulted to examine the efficiency of an evaporative cooling system. In general, however, these systems cool the air about $5-7^{\circ} \mathrm{C}$ above the wet bulb temperature. For instance, a midday air temperature of $35^{\circ} \mathrm{C}$ along with a wet bulb temperature of $20^{\circ} \mathrm{C}$ and a system efficiency of 0.6 will deliver an air temperature of $25^{\circ} \mathrm{C}$. Thus, areas with a wet bulb temperature of $20^{\circ} \mathrm{C}$ or less may use evaporative cooling systems with good results. This includes the mountainous areas and most of the desert. When the wet bulb temperature is above $20^{\circ} \mathrm{C}$, evaporative cooling systems may be inefficient to bring about adequate thermal comfort. Figure 9 shows that the Jordan Valley, some desert areas and the northwestern part of the country have relatively high wet bulb temperature, rendering evaporative cooling systems in these areas rather inefficient in bringing about adequate thermal comfort. 
The widespread lack of climatological data in many countries is a major problem facing researchers and planners. These data are prerequisite for successful implementation of many operational projects like construction of dams, assessment of irrigation water needs, estimation of evaporation and evapotranspiration from dams and agricultural fields, evaluation of heating and cooling loads, to name a few. The wide availability of remote sensing data, powerful GIS tools and computational methods have revolutionized data handling, processing and visualization. meteorological data across a regional scale. The generated data were extended to derive the spatial distribution of thermal comfort across Jordan as a case study. It was shown that the procedure was able to generate spatially continuous high- resolution maps of climatological elements and infer detailed information about their spatial distribution. It was shown for instance, that the widespread cold conditions across the desert in winter is physically linked to the ambient water vapor pressure. Point measurements represent an important database, given their long record. Point measurements suffer from two major weaknesses, the first one is that they represent their immediate surroundings, and thus measured meteorological elements represent a small area particularly in rugged terrains where climate gradient is very large. The second disadvantage is their very limited number, particularly in third world countries due to logistics and financial constraints. For instance, the major portion of the country of Jordan is not covered by any measuring stations, and thus any planning for a project will be based on intuition or guessing, leading most of the time to flawed outcome.

310 Thermal comfort for cities and small geographic localities has usually been reported in the literature using point measurements. This type of evaluation is adequate for urban centers encountering similar meteorological forcings across the landscape. Urban area spanning a large topographic gradient will experience very different thermal comfort levels. Urban centers built in mountainous areas represent a prime example, and thus the fine spatial details in meteorological conditions influenced by topographic variations should be resolved adequately. The present paper presents an efficient algorithm to generate a big dataset of climatological elements across a large area. Jordan was used as a case study to demonstrate the efficiency of this procedure. Generated climatological data were used to derive high resolution thermal comfort levels across the country. 


\section{Statements and Declarations}

There is no financial or other competing of interests.

\section{References}

Anderson GB, Bell ML, Peng RD. 2013. Methods to calculate the heat index as an exposure metric in environmental health research. Environ Health Perspect. 121:1111-1119; http://dx.doi.org/10.1289/ehp.1206273

Apaydin, H., Sonmez, F. K., Yildirim, Y. E. (2004) Spatial interpolation techniques for climate data in the GAP region in Turkey, Climate Research, 28: 31-40.

ASHRAE (2009) Handbook-Fundamentals. Atlanta: American Society of Heating, Refrigerating and Air-Conditioning Engineers, Inc

Basediya, A., Samuel, V., Beera, V., (2013). Evaporative cooling system for storage of fruits and vegetables - a review, J Food Sci Technol., 50(3): 429-442. 10.1007/s13197-011-0311-6

Blazejczyk, K., Epstein, Y., Jendritzky, G., Staiger, H., Tinz, B. (2010) Comparison of UTCI to selected thermal indices, Int. J. Biometeorol., 56, 515-535, DOI 10.1007/s00484-011-0453-2

Brager, Gail S.; de Dear, Richard J. (1998). "Thermal adaptation in the built environment: a literature review". Energy and Buildings. 27 (1): 83-96, doi:10.1016/S0378-7788(97)00053-4. ISSN 03787788.

Camargo JR. Evaporative cooling: water for thermal comfort. An Interdisciplinary. J Applied Sci. 2007;3:51-61.

De Dear, R. J., Brager, G. S. (2002). Thermal comfort in naturally ventilated buildings: revisions to ASHRAE Standard 55. Energy and buildings, 34(6), 549-561.

Emmendorfer L.R., Dimuro G.P. (2020) A Novel Formulation for Inverse Distance Weighting from Weighted Linear Regression. In: Krzhizhanovskaya V. et al. (eds) Computational Science - ICCS 2020. ICCS 2020. Lecture Notes in Computer Science, vol. 12138. Springer, Cham. https://doi.org/10.1007/978-3-030-50417-5_43 
Fabbri, K., 2015. A Brief History of Thermal Comfort: From Effective Temperature to Adaptive Thermal Comfort, DOI:10.1007/978-3-319-18651-1_2 (in: Indoor Thermal Comfort Perception).

Fang, L; Wyon, DP; Clausen, G; Fanger, PO (2004). "Impact of indoor air temperature and humidity in an office on perceived air quality, SBS symptoms and performance". Indoor Air. 14 Suppl 7: 7481. doi:10.1111/j.1600-0668.2004.00276.x. PMID 15330775.

Fergus, N., 2001. Characterizing occupant behavior in buildings, Proceedings of the Seventh International IBPSA Conference. Rio de Janeiro, Brazil. pp. 1073-1078.

Humphreys, M., Nicol, Fergus, 2000. Outdoor Temperature and Indoor Thermal Comfort: Raising the Precision of the Relationship for the 1998 ASHRAE Database of Field Studies, ASHRAE Symposia, publication/284652345.

Jeffrey, S., Carter, J., Moodie, K., Beswick, A (2001). Using spatial interpolation to construct a comprehensive archive of Australian climate data, Environmental Modelling and Software, 16, 309-330.

Matzarakis A., Amelung, B (2008) Physiological Equivalent Temperature as Indicator for Impacts of Climate Change on Thermal Comfort of Humans, in M.C. Thomson et al. (eds.), Seasonal Forecasts, Climatic Change and Human Health, Springer Science.

Mazinyo, S., Nel, W., Iortyom, E., (2017). Climate Variability and Heat Stress Index have Increasing Potential Ill-health and Environmental Impacts in the East London, South Africa, International Journal of Applied Engineering Research, 12, (17), 6910-6918.

Marx W., Haunschild R, Bornmann L. (2021) Heat waves: a hot topic in climate change research., Theor. Appl. Climatol. 2021 Sep 3:1-20. doi:10.1007/s00704-021-03758-y.

Mistry, M. (2020). A high spatiotemporal resolution global gridded dataset of historical human discomfort indices, Atmosphere 2020, 11, 835; doi:10.3390/atmos11080835

Orimoloye, I., Mazinyo, S., Nel, W., Iortyom E. (2017) Climate Variability and Heat Stress Index have Increasing Potential Ill-health and Environmental Impacts in the East London, South Africa, International Journal of Applied Engineering Research, 12, 6910-6918

Oliveira, S., Andrade, H. (2007) An initial assessment of the bioclimatic comfort in an outdoor public space in Lisbon, Int. J. Biometeorol., 52:69-84, doi: 10.1007/s00484-007-0100-0

Orosa, J. A., 2009. On the Origins of Thermal Comfort, European Journal of Scientific Research, 34 (4), 561-567. 
Oroud, IM (1997). Diurnal Evaporation from fresh and hypersaline shallow ponds in a hot, dry environment. Physical Geography. 18, no. 4, 363- 382.

Oroud, IM (2011). Evaporation from the Dead Sea and its implications on its water balance, Theoretical and Applied Climatology, DO1 10.1007/\$00704-0452-6.

Schlatter T.W. (1987) Temperature-humidity index. In: Climatology. Encyclopedia of Earth Science. Springer, Boston, MA. doi.org/10.1007/0-387- Mistry, M. (2020). A high spatiotemporal resolution global gridded dataset of historical human discomfort indices, Atmosphere 2020, 11, 835; doi:10.3390/atmos1108083530749-4_176

Schweiker, M., Fuchs, X., Becker, S., Shukuya, M., Dovjak, M., Hawighorst, M., Kolarik, J (2017) Challenging the assumptions for thermal sensation scales, Building Research and Information, 45:5, 572-589, DOI: 10.1080/09613218.2016.1183185

Steadman, R. G (1979). "The Assessment of Sultriness. Part I: A Temperature-Humidity Index Based on Human Physiology and Clothing Science". J. Appl. Meteorol. 18 (7): 861-873. doi: 10.1175/1520-04501.

Steadman, R. G. (y 1979). "The Assessment of Sultriness. Part II: Effects of Wind, Extra Radiation and Barometric Pressure on Apparent Temperature". Journal of Applied Meteorology. 18 (7): 87485, doi:10.1175/1520-04502.

Steadman, R. G. (y 11984). A universal scale of apparent temperature, J. Climate A.M, 23, 1674- 1687. Stull, R. (2011) Wet-Bulb Temperature from Relative Humidity and Air Temperature. J. Appl. Meteorol. Climatol., 50, 2267-2269.

Tseliou, A., Tsiros, I., Lykoudis, S, Nikolopoulou, M. (2010) An evaluation of three biometeorological indices for human thermal comfort in urban outdoor areas under real climatic conditions, Building and Environment 45 (2010) 1346-1352, doi:10.1016/j.buildenv.2009.11.009

Yan, Y., Xu, Y., Yue, S. (2021) A high-spatial-resolution dataset of human thermal stress indices over South and East Asia, Scientific Data, 1 (8), 229, 10.1038/s41597-021-01010-w 
401 List of Figures

402 Figure 1. Location of the study area.

403 Figure 2. Topography of study area along with the measuring climatological stations.

404 Figure 3. Flowchart of steps used to carry out the investigation.

405 Figure 4. The spatial distribution of average monthly air temperature in July and January.

406 Figure 5. The spatial distribution of indoor apparent temperature in July and January.

407 Figure 6. The spatial distribution of ambient vapor pressure across Jordan in January.

408 Figure 7. A scatterplot of the relationship between indoor thermal comfort and elevation.

409 Figure 8. The average monthly indoor apparent temperature for twenty-two locations.

410 Figure 9. Spatial distribution of the wet bulb temperature during July.

411

412

413 List of Tables

1- Table 1. Meteorological stations along with their geographic and climatological properties 
Figures

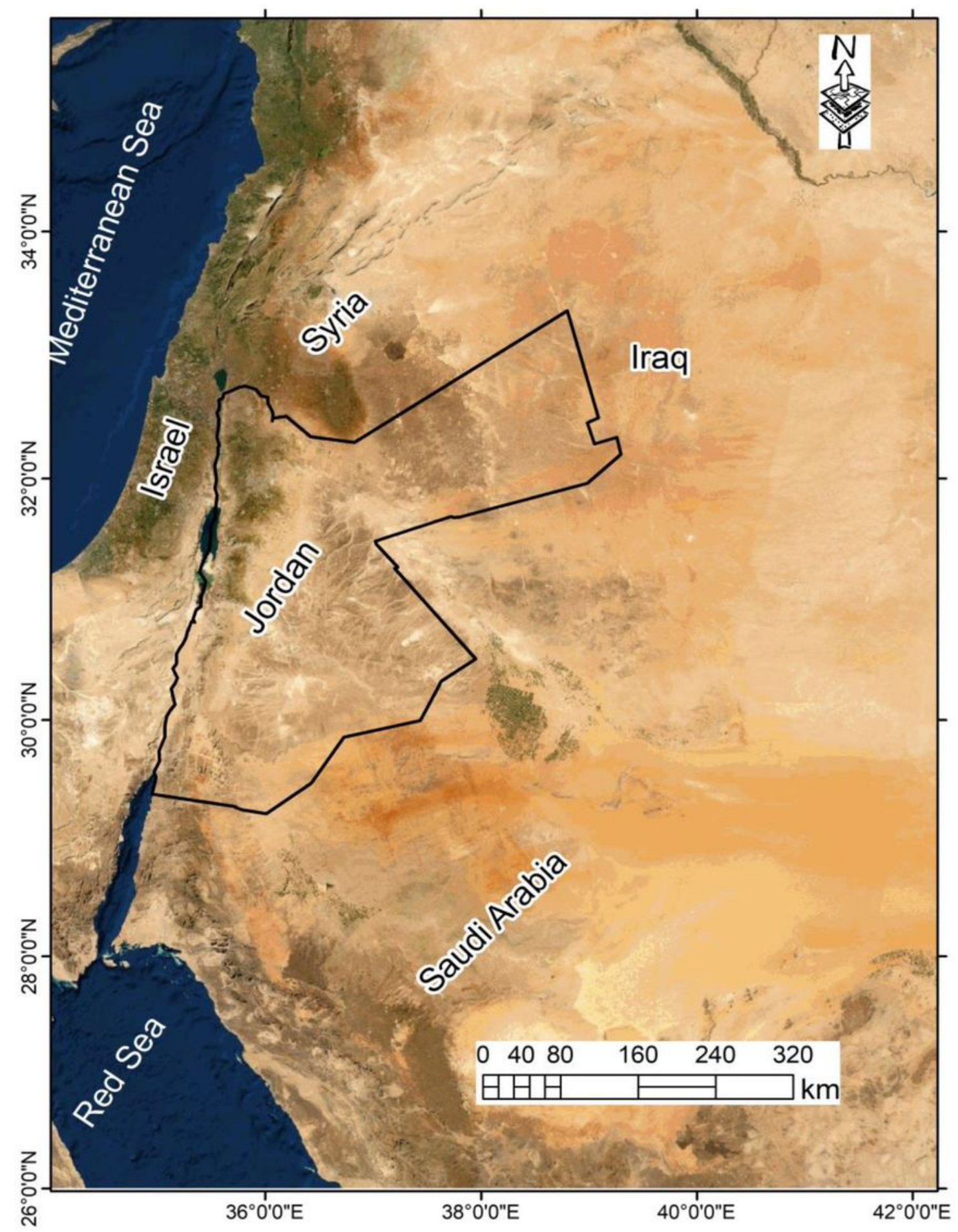

Figure 1

Location of the study area. 


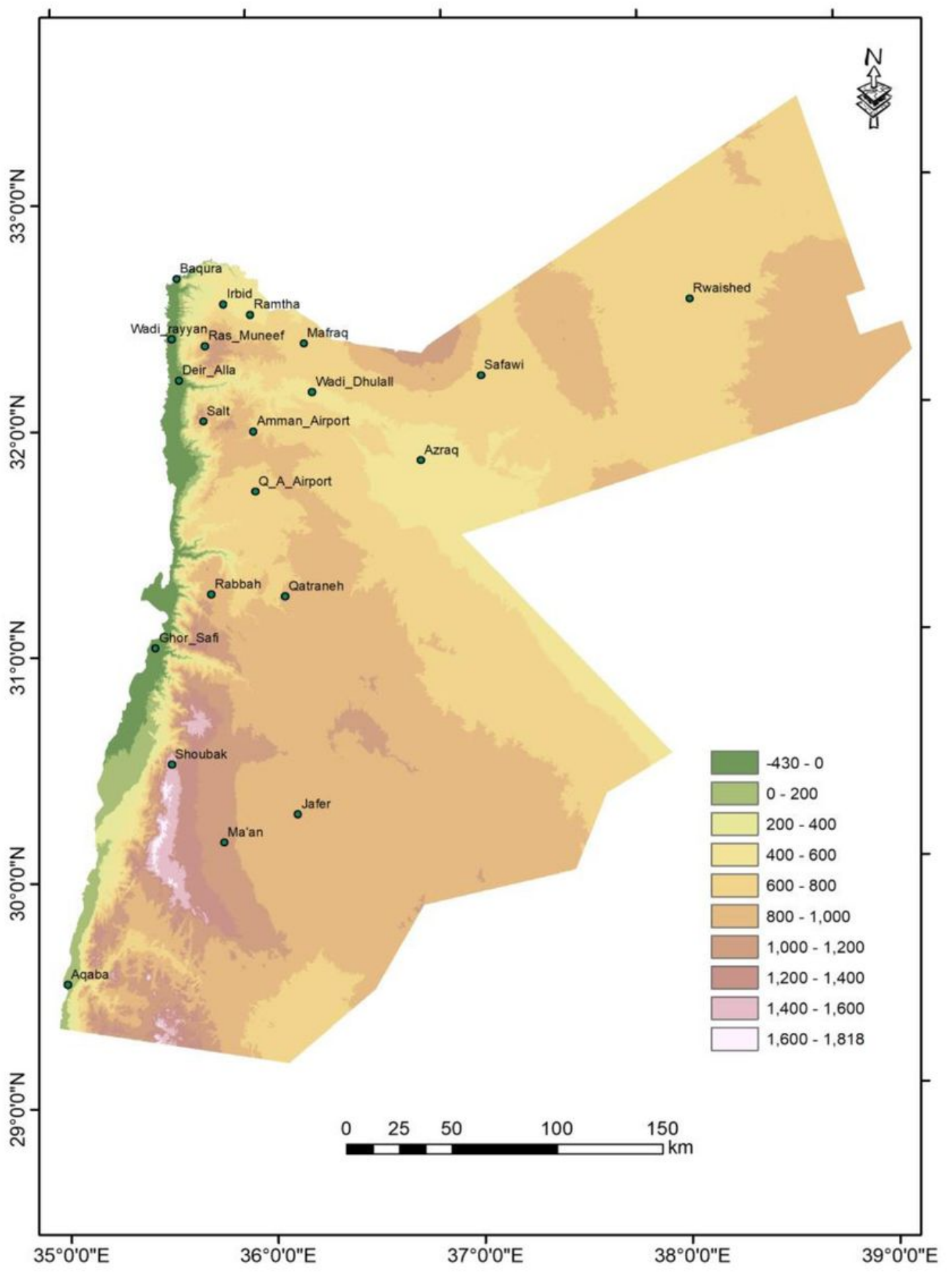

Figure 2

Topography of study area along with the measuring climatological stations. 


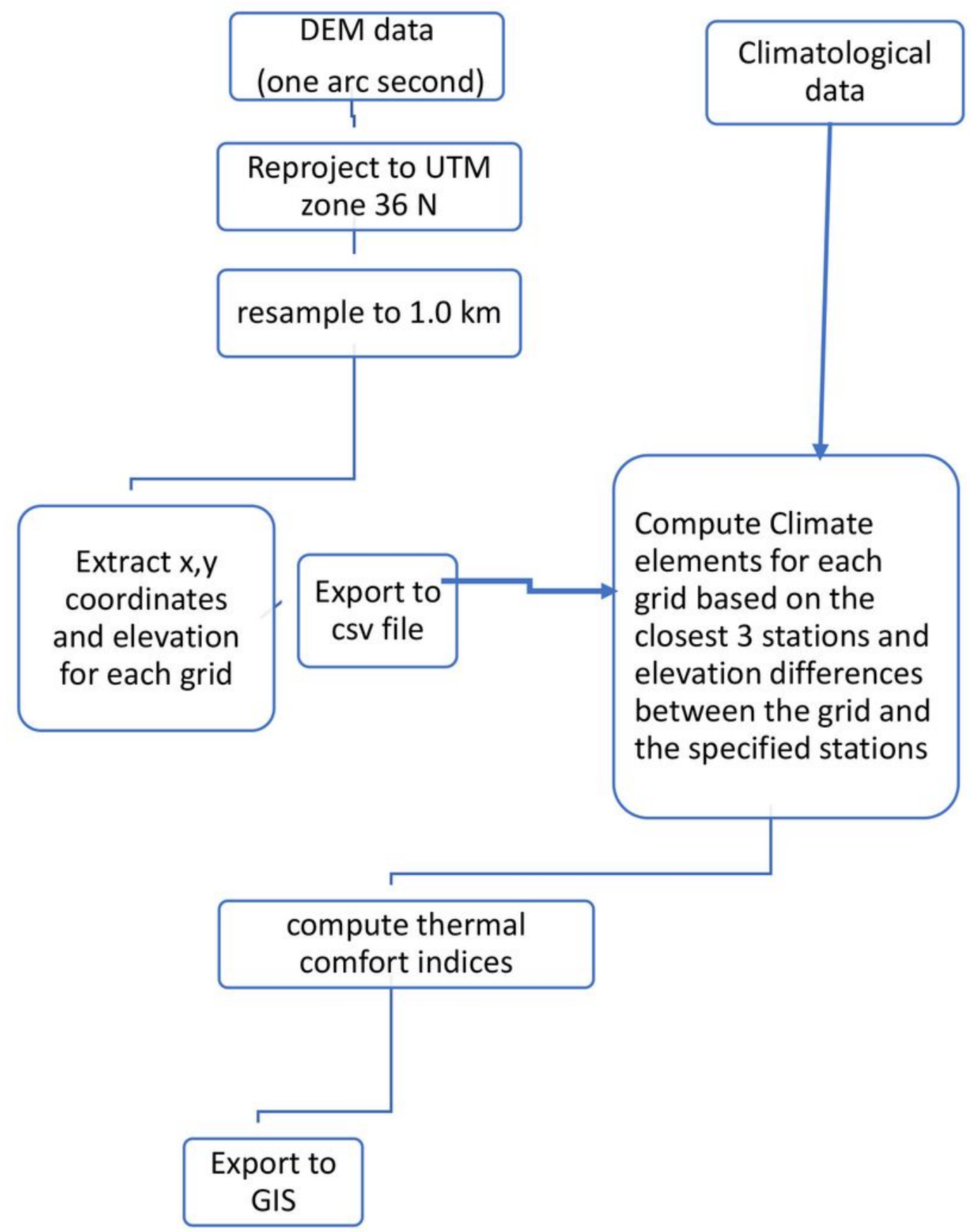

Figure 3

Flowchart of steps used to carry out the investigation. 

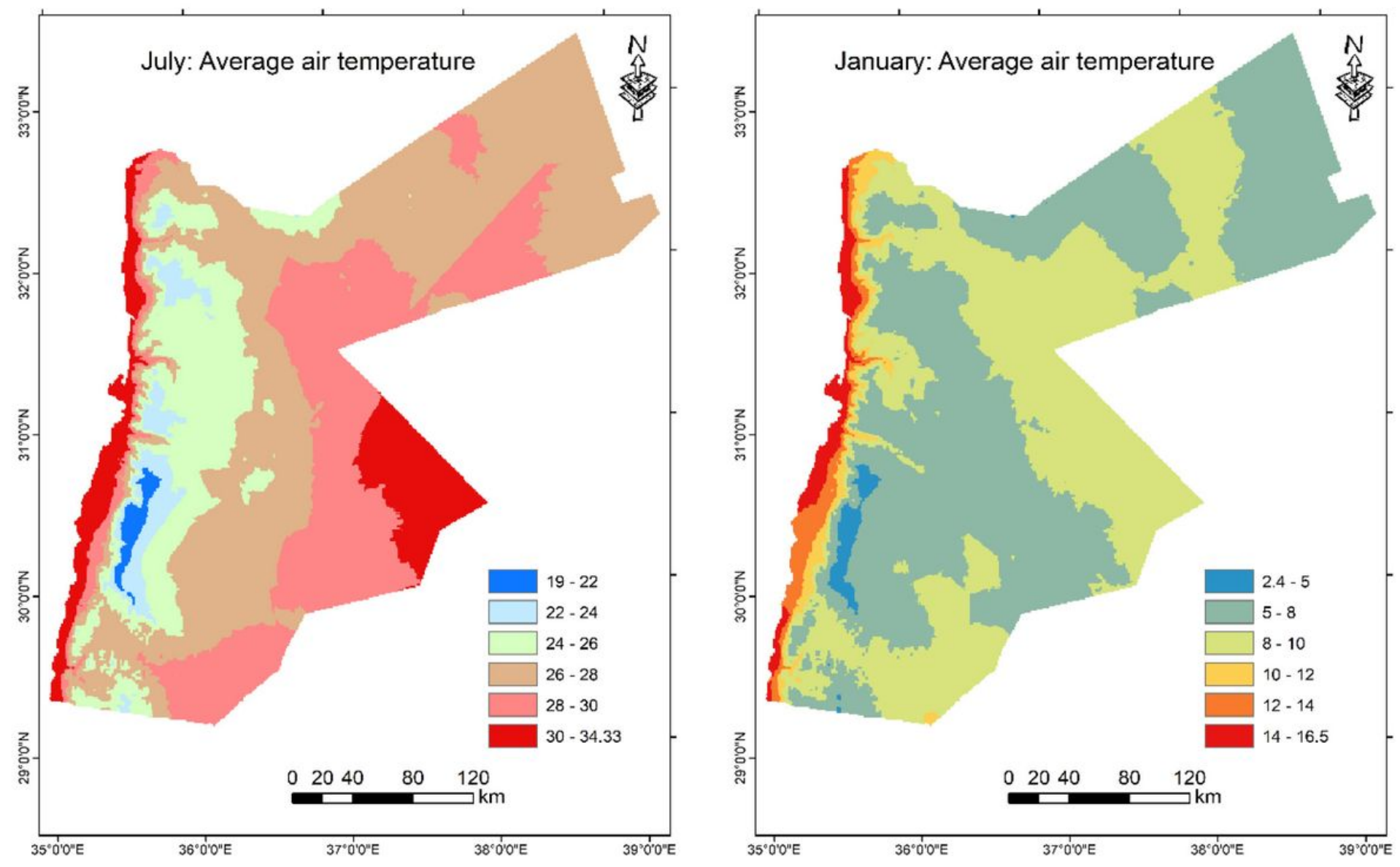

Figure 4

The spatial distribution of average monthly air temperature in July and January. 

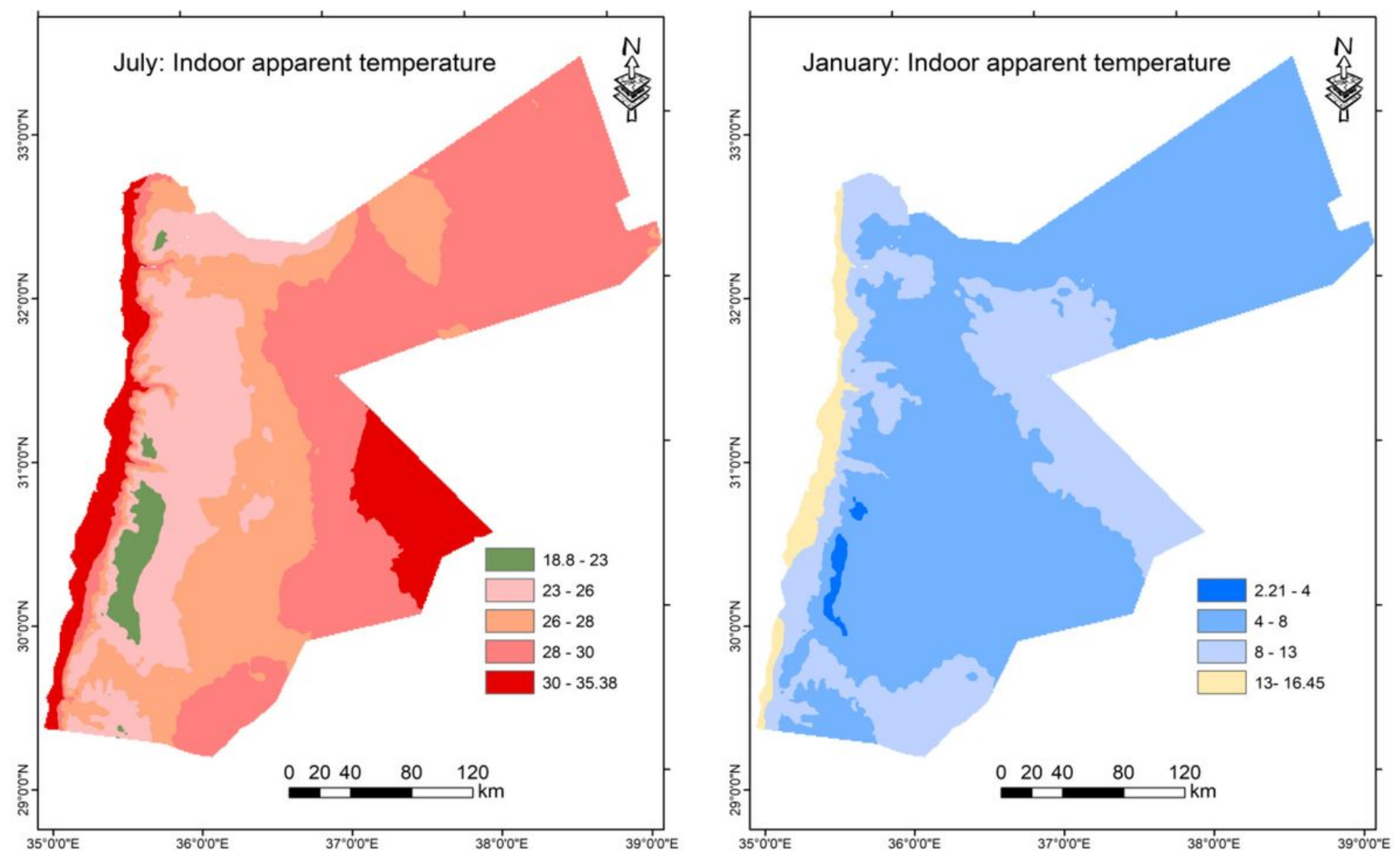

Figure 5

The spatial distribution of indoor apparent temperature in July and January. 


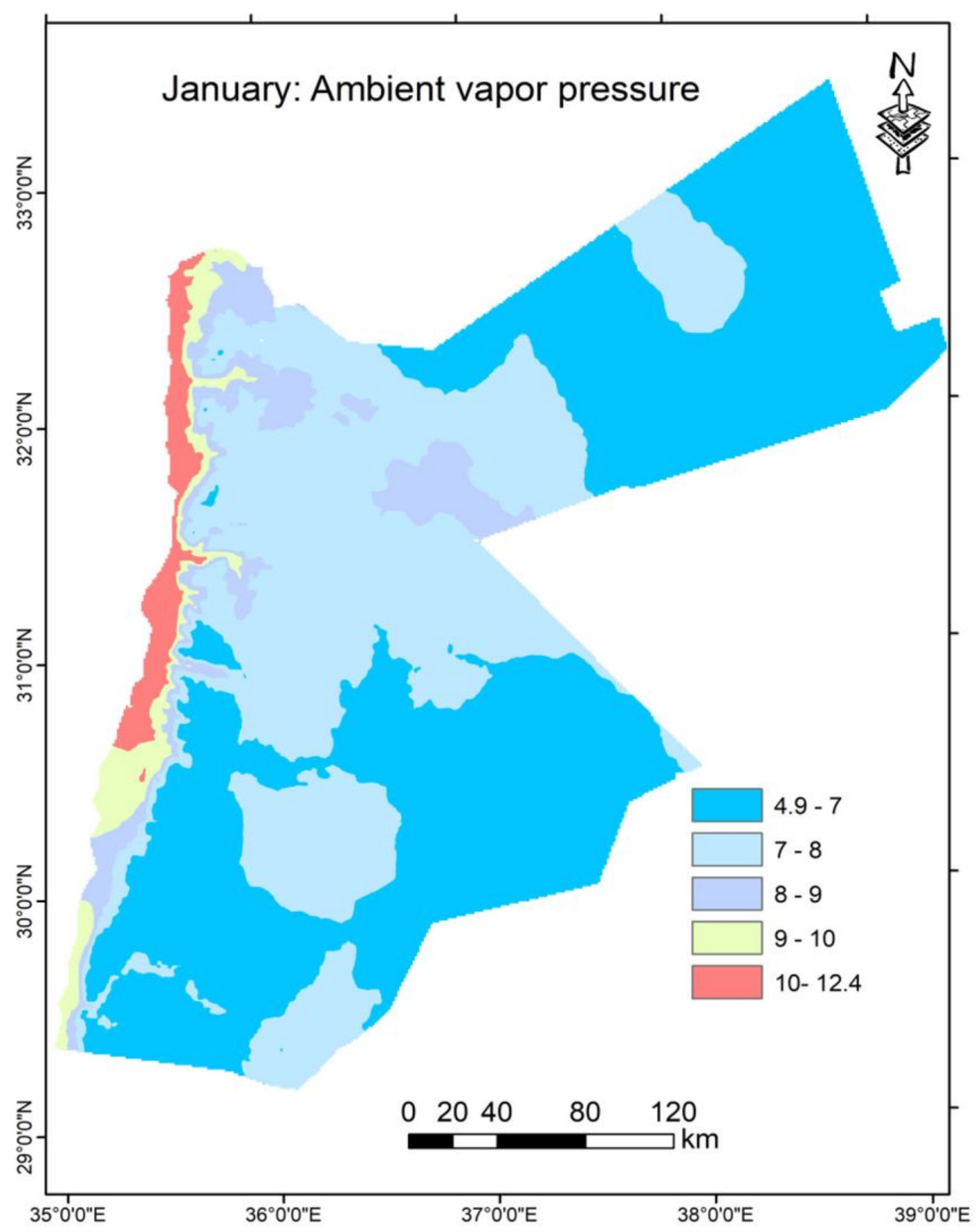

Figure 6

The spatial distribution of ambient vapor pressure across Jordan in January. 


\begin{tabular}{|c|c|c|c|c|c|c|c|c|c|c|c|c|c|c|c|}
\hline STATION & Long. & Lat. & Elev. & SEPT & OCT & NOV & DEC & JAN & FEB & MARCH & APR & MAY & JUNE & JULY & AUG \\
\hline Shobak & 35.53 & 30.5 & 1365 & 18.70 & 15.19 & 9.60 & 5.42 & 3.60 & 4.42 & 7.04 & 11.19 & 14.92 & 18.32 & 20.59 & 20.73 \\
\hline RasMunif & 35.75 & 32.4 & 1150 & 21.44 & 18.64 & 12.34 & 7.37 & 5.12 & 5.47 & 8.31 & 12.99 & 17.44 & 20.61 & 22.52 & 22.56 \\
\hline Q_A_Airp & 35.98 & 31.7 & 722 & 22.60 & 19.54 & 13.47 & 8.72 & 7.02 & 7.93 & 10.43 & 15.00 & 19.08 & 22.17 & 24.23 & 24.16 \\
\hline Rabbah & 35.75 & 31.3 & 920 & 22.63 & 19.92 & 14.43 & 9.46 & 7.42 & 7.97 & 10.38 & 14.49 & 18.71 & 22.15 & 24.28 & 24.30 \\
\hline Mafraq & 36.25 & 32.4 & 686 & 23.77 & 20.27 & 13.83 & 8.77 & 7.04 & 8.07 & 10.92 & 15.53 & 20.11 & 23.57 & 25.47 & 25.43 \\
\hline Salt & 35.73 & 32 & 796 & 23.77 & 21.38 & 15.28 & 10.44 & 8.04 & 8.14 & 10.82 & 15.34 & 20.06 & 23.25 & 25.50 & 25.50 \\
\hline Ramtha & 35.98 & 32.5 & 590 & 24.31 & 21.20 & 15.14 & 10.22 & 8.28 & 8.96 & 11.25 & 16.02 & 20.53 & 23.81 & 25.82 & 26.32 \\
\hline Qatraneh & 36.12 & 31.3 & 768 & 23.78 & 20.25 & 14.14 & 9.42 & 7.69 & 8.46 & 11.33 & 16.20 & 20.42 & 23.56 & 25.82 & 26.00 \\
\hline Maan & 35.78 & 30.2 & 1069 & 24.66 & 20.24 & 13.44 & 8.72 & 6.89 & 8.22 & 11.37 & 16.19 & 20.44 & 24.06 & 25.88 & 26.44 \\
\hline Irbid & 35.85 & 32.6 & 616 & 24.48 & 21.71 & 15.70 & 10.38 & 8.32 & 9.34 & 11.64 & 15.57 & 20.42 & 24.62 & 25.93 & 25.89 \\
\hline AmmanA & 35.98 & 32 & 781 & 24.73 & 21.41 & 14.78 & 9.53 & 7.64 & 8.47 & 11.12 & 15.53 & 20.27 & 24.19 & 26.42 & 26.54 \\
\hline WadDhul & 36.28 & 32.2 & 580 & 25.71 & 21.48 & 14.27 & 9.15 & 7.57 & 8.84 & 11.93 & 16.71 & 21.48 & 25.19 & 27.45 & 27.60 \\
\hline Jaffer & 36.15 & 30.3 & 856 & 25.96 & 21.25 & 14.17 & 8.85 & 7.17 & 8.73 & 12.19 & 17.37 & 21.87 & 25.41 & 27.50 & 27.97 \\
\hline Rwaished & 38.2 & 32.5 & 683 & 26.92 & 21.90 & 14.32 & 9.07 & 7.27 & 8.87 & 12.40 & 17.38 & 22.29 & 26.53 & 28.99 & 29.37 \\
\hline Safawi & 37.13 & 32.2 & 674 & 27.32 & 22.55 & 14.77 & 9.25 & 7.38 & 8.90 & 12.39 & 17.46 & 22.60 & 26.71 & 29.02 & 29.24 \\
\hline ZARKA & 36.117 & 32.1 & 555 & 26.96 & 23.81 & 16.24 & 11.08 & 9.30 & 10.11 & 13.46 & 18.15 & 22.74 & 26.71 & 29.26 & 29.16 \\
\hline Azraq & 36.82 & 31.8 & 521 & 27.94 & 23.23 & 15.26 & 9.94 & 8.38 & 9.81 & 13.33 & 18.75 & 23.75 & 27.53 & 29.65 & 29.93 \\
\hline Baqurah & 35.62 & 32.7 & -170 & 30.77 & 27.01 & 20.76 & 15.24 & 13.36 & 13.97 & 16.50 & 21.16 & 26.11 & 30.23 & 32.64 & 32.98 \\
\hline DeirAlla & 35.62 & 32.2 & -224 & 31.18 & 28.22 & 22.34 & 16.66 & 14.64 & 15.21 & 17.87 & 22.38 & 26.89 & 30.77 & 33.01 & 33.28 \\
\hline W_Ryan & 35.58 & 32.4 & -200 & 31.66 & 27.51 & 20.55 & 14.95 & 13.20 & 13.82 & 16.44 & 21.10 & 26.06 & 30.50 & 33.09 & 33.68 \\
\hline Aqaba & 35 & 29.6 & 51 & 31.34 & 27.52 & 21.16 & 15.69 & 14.09 & 15.50 & 18.61 & 23.15 & 27.64 & 31.56 & 33.89 & 34.10 \\
\hline Ghor_Saf & 35.47 & 31 & -350 & 33.70 & 29.65 & 22.58 & 17.05 & 15.59 & 16.68 & 19.80 & 24.14 & 28.72 & 32.69 & 35.67 & 36.03 \\
\hline
\end{tabular}

\section{Figure 7}

A scatterplot of the relationship between indoor thermal comfort and elevation. 


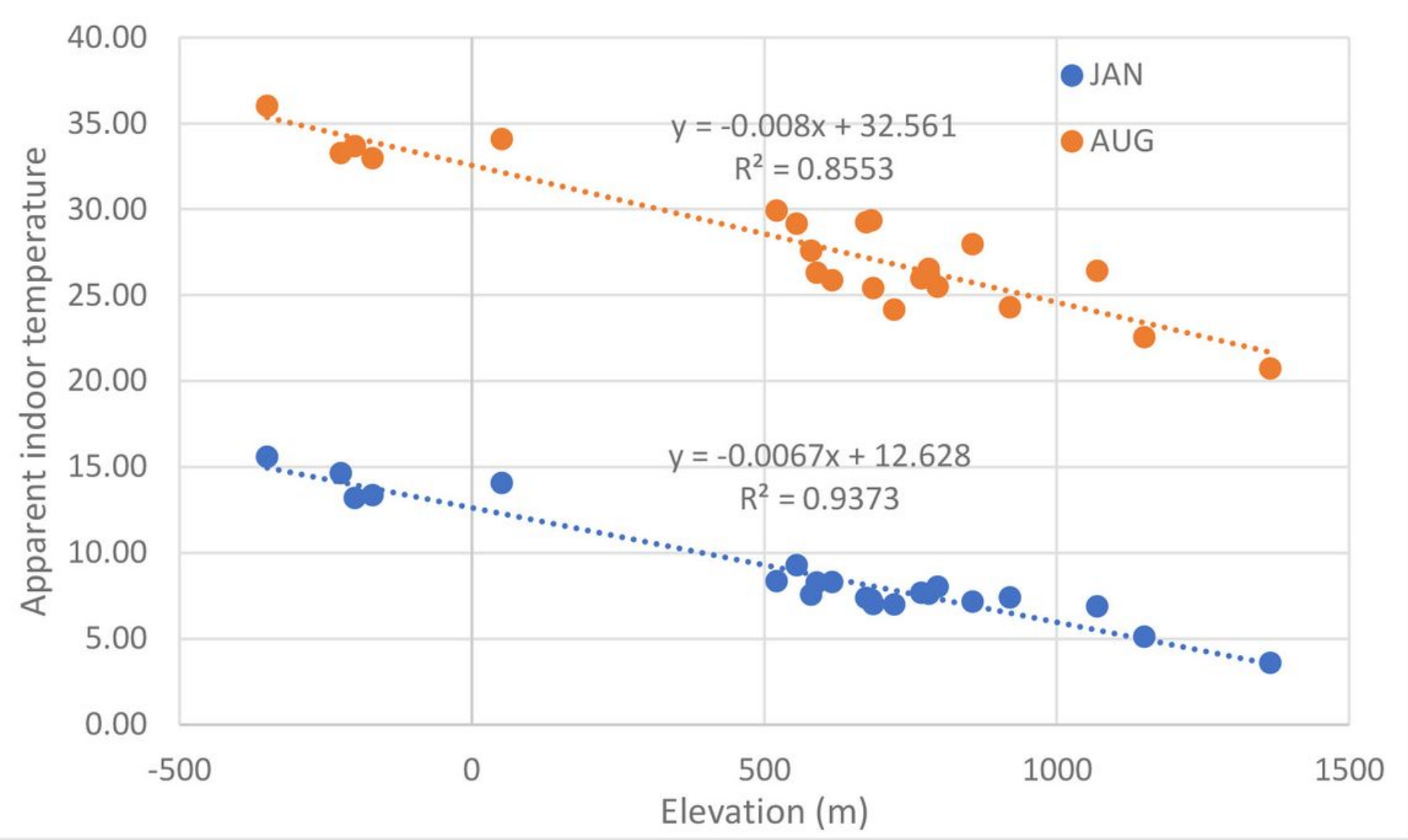

Figure 8

The average monthly indoor apparent temperature for twenty-two locations. 


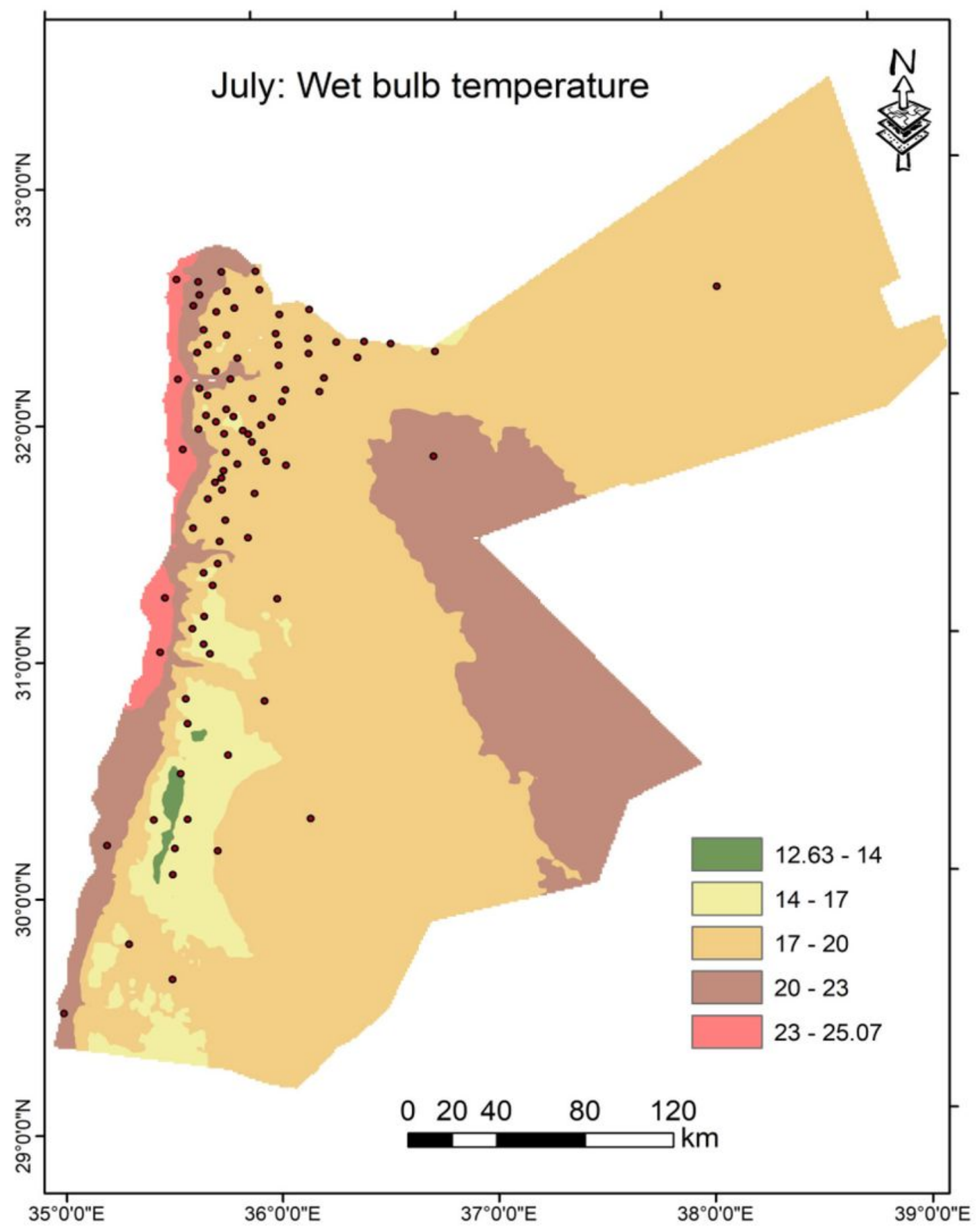

Figure 9

Spatial distribution of the wet bulb temperature during July. 